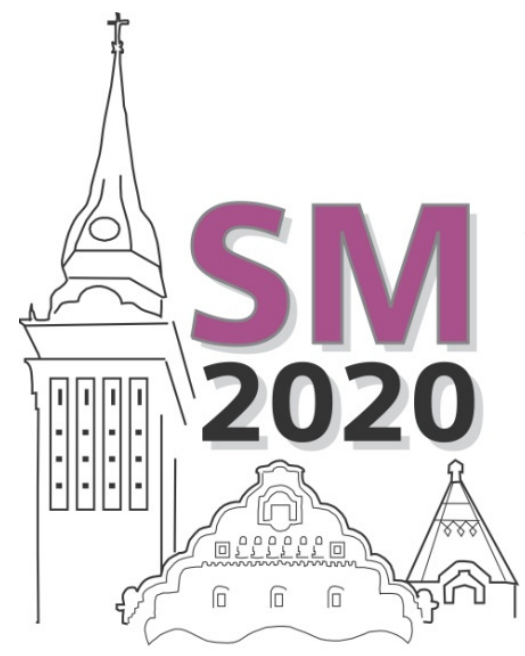

DOI: 10.46541/978-86-7233-386-2_38

25th International Scientific Conference

Strategic Management and Decision Support Systems

in Strategic Management

$19^{\text {th }}$ May, 2020, Subotica, Republic of Serbia

Laslo Šereš

University of Novi Sad

Faculty of Economics in Subotica,

Subotica, Serbia

laslo.seres@ef.uns.ac.rs

\author{
Veselin Pavlićević \\ University of Novi Sad \\ Faculty of Economics in Subotica, \\ Subotica, Serbia \\ pavlicevic@ef.uns.ac.rs
}

\author{
Goran Petrović \\ Institute of Field and Vegetable Crops, \\ Novi Sad, Serbia \\ goran.petrovic@nsseme.com
}

\title{
Learning Analytics: An Updated View
}

\begin{abstract}
Learning analytics has been a hot topic in the education industry for several years. Given its diverse roots (business intelligence, web analytics, educational data mining, etc.), researchers and practitioners have approached learning analytics from a range of perspectives. Although many studies concerning learning analytics have highlighted its great potential for improving learning practice, there has not been much success in the transfer of the suggested potential into the practice of higher education. This clearly indicates a need for rethinking not only the goals that can be achieved using learning analytics, but also what must be done in order to attain these goals. The aim of the descriptive research presented in this paper is to provide an honest and updated view of where we are, the real benefits, and the challenges to be overcome when using learning analytics as educational technology. This paper emphasizes that a deeper understanding of students' learning experiences as well as a more realistic approach to both the interconnected concepts of learning analytics and the organizational practices that it supports can dramatically accelerate the improvement of student success at institutions.
\end{abstract}

Keywords: Learning analytics, Technology-enhanced learning, Action analytics, Learning

\section{INTRODUCTION}

The integration of digital technology into higher education (HE) influences both teaching and learning practices, and allows access to data, mainly available from online learning environments, that can be used to improve students' learning. Online learning facilitating the use of asynchronous and synchronous interaction and communication within a virtual environment (Broadbent \& Poon, 2015), became an integral part of HE, "and now it needs to turn its focus, from providing access to university education, to increasing its quality" (Lee, 2017, p. 15). HE institutions are implementing Learning Analytics (LA) systems to better understand and support student learning (Schumacher \& Ifenthaler, 2018). There is an evolving interest in LA among not only practitioners but also researchers in Technology-Enhanced Learning (TEL). LA emerges as a fast-growing and multi-disciplinary area of TEL (Ferguson, 2012), which forms its own domain (Strang, 2016).

Learning analytics can be understood as the analysis and representation of data about learners in order to improve learning and provides teachers with a new lens through which they can better understand and advance the education. In LA, information about learners and learning environments is used to "access, elicit, and analyse them for modelling, prediction, and optimization of learning processes" (Mah, 2016, p. 288). It is rooted in the dramatic increase in the quantity of data about learners and linked to management approaches that focus on quantitative metrics, which are sometimes 
opposed to an educational sense of teaching. However, learning analytics offers new routes for teachers to understand their students, and hence to make effective use of their limited resources.

There are multiple definitions of learning analytics, but the most popular one comes from the $1^{\text {st }}$ International Conference on Learning Analytics (LAK 2011): "Learning analytics is the measurement, collection, analysis, and reporting of data about learners and their contexts, for purposes of understanding and optimizing learning and the environments in which it occurs." There are three crucial elements involved in this definition: Data, Analysis and Action.

Learning analytics data is the set of information collected about the student, the learning environment, the learning interactions, and the learning outcomes. This information is usually gathered while the learning process is taking place. Data comes from many sources:

- Student Information Systems (SIS): provide demographic and academic data;

- Learning Management Systems (LMS): provide students' activity records as well as students' performance information;

- Other systems: provide multiple types of information. Depending on how far we want to take our data collection, we could potentially collect library records, e-book consumption patterns, social network information, etc.

Data analysis is the process of obtaining actionable insights from the collected data (Pic. 1). It is based on a set of mathematical and statistical algorithms known as machine learning techniques. Generally speaking, more sophisticated data analysis algorithms lead to better insights. However, complex algorithms also impose higher demands on the collected data in terms of volume, type, timeframe, etc. Selecting the right data and algorithms is the art behind properly implemented learning analytics processes.
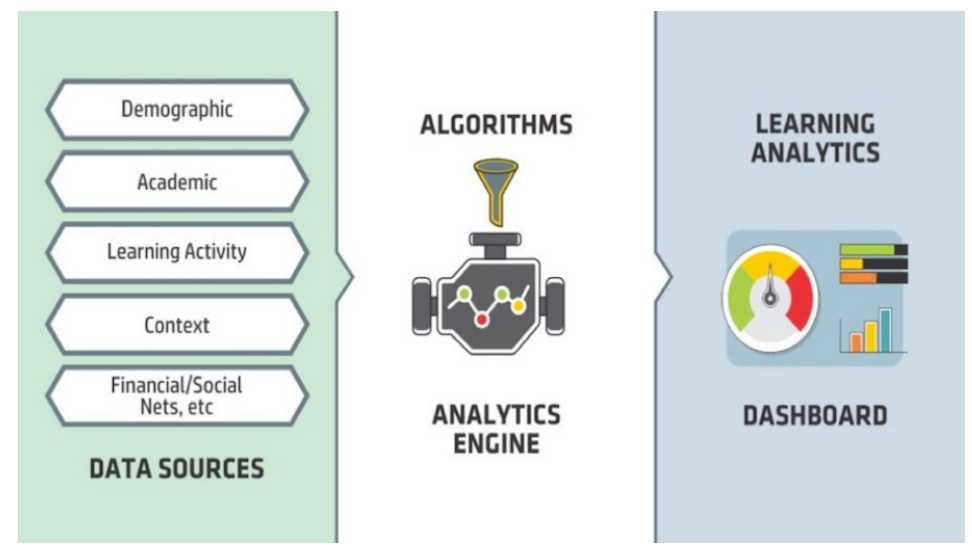
Picture 1: Learning analytics as a process of obtaining insights from the collected data
Source: https://www.iadlearning.com/learning-analytics-2018/

Taking action is the ultimate goal of any learning analytics process. The absence of action is a complete failure. It does not matter how good or bad one's predictions are if they are unable or not willing to act on them. Although this is usually understood, it should be noted that the right internal processes need to be in place for interventions to happen.

As in any field of activity, particularly new ones, distinctions between related efforts are often difficult to make and subject to change; however, broad outlines can be drawn. There are two emerging areas that significantly overlap with learning analytics. The first is academic analytics, which is the use of business intelligence in education. This tends to focus more at the institutional and national level, rather than on individual students and courses (Long \& Siemens, 2011). The second is educational data mining (EDM), which seeks to develop methods for analyzing educational data, and tends to focus more on the technical challenges than on the pedagogical questions (Ferguson, 2012). Learning analytics, on the other hand, is primarily concerned with learning - the key concern of LA is the use of insights gathered from data to improve learning and generate 'actionable intelligence' (Campbell, De Blois \& Oblinger, 2007).

Campbell \& Oblinger (2007) set out five steps of the LA process: Capture, Report, Predict, Act, Refine. Clow (2012) places this as the central idea in his Learning Analytics Cycle (Fig. 2). The cycle starts with learners, who generate data, which is processed into metrics used to inform interventions, which in turn affect learners. The learners may be students in a traditional higher education setting, or in less formal contexts. The data can include demographic information, online activity, assessment data, and final destination data. The metrics can be presented in a wide range of ways: from a simple indication of whether learning progress is being made, to a comparison of outcomes to some benchmark, or a visual picture of activity in an online forum. The interventions again range widely, from students taking action in the light of metrics showing their activity compared to that of their peers, to teachers contacting students identified as requiring extra help. 


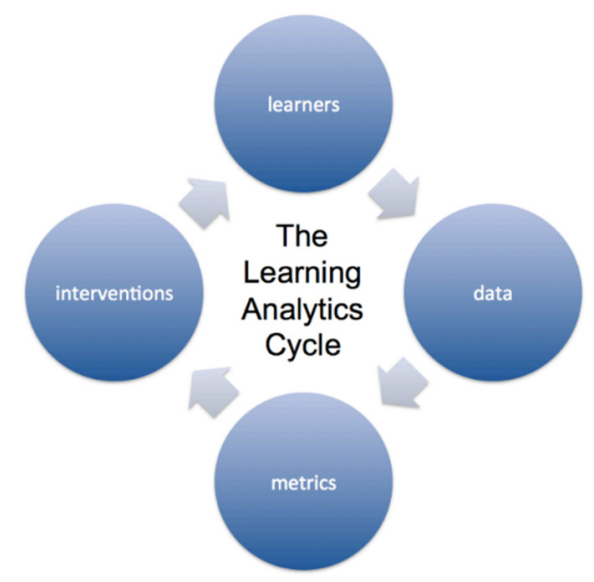

Picture 2: The Learning Analytics Cycle Source: Clow, 2012

Learning analytics has a range of drivers and facilitators. Firstly, there is the pressure towards performance management, metrics, and quantification. Secondly, there is an increasing volume of data available about learners and learning, particularly as more learning takes place online in Learning Management Systems or Virtual Learning Environments (LMS/VLEs). Every page visited, every interaction, every click can in theory be recorded and stored. Thirdly, statistical and computational tools for managing large datasets and facilitating interpretation have become more accessible over the years.

As an emerging and promising activity it is attracting the interest of a growing research community. There are now conferences and special issues dedicated to this topic, as well as an special international research network: SoLAR, the Society for Learning Analytics Research (http://www.solaresearch.org/). Along with the growing interest, the offer of learning technology is learning analytics packages as well.

\section{LEARNING ANALYTICS: AS IT IS}

Learning analytics is not so much an established academic discipline with well-defined methodological approaches as it is a field of enquiry and a random selection of 'great' techniques, tools, and methodologies. This eclectic approach is both a strength and a weakness: it facilitates rapid development and the ability to build on established practice and findings, but it, this day, lacks a coherent, articulated epistemology of its own.

Indeed, vendors of learning technology are providing more and more analytics packages: for instance, Blackboard, Desire2Learn, Instructure and Tribal have all released analytics tools, and there is also activity in the Moodle community. The high-profile providers of Massively Open Online Courses (MOOCs) - Coursera, Udacity and edX - are all using analytics tools to inform their practice.

Different packages provide different levels of sophistication in terms of data analysis. Most of the existing solutions are providing only descriptive learning analytics: These types of analytics are reactive. They allow understanding of the past and, based on this understanding, influence the future. Lately, there is a noticeable shift towards predictive learning analytics: These types of analytics are proactive. They influence the present and, therefore, improve ongoing learning processes. Crossing the bridge that separates descriptive from predictive analytics is not easy: it requires the right data (which many organizations do not really have) and the appropriate algorithms. As we already mentioned, selecting the right data and algorithms is the art behind properly implemented learning analytics processes. Below, we describe some of the methods and techniques that currently attract the most attention when it comes to applying LA to practice.

As a reflection of the desire to move from descriptive to predictive analytics, predictive modeling has become one of the most current issues in LA. Predictive modelling can be applied to education in a wide range of ways. The best-established application is estimating how likely it is that individual students will complete a course and, using those estimates to target support to students to improve the completion rate. Sophisticated mathematical techniques like factor analysis and logistic regression are applied to a large dataset containing information about previous students on the course. A model is developed from this data, and then applied to the information available for current students, to give a quantified prediction of whether each student will complete the course. In principle, predictive modelling is not profoundly different from a traditional teacher noticing which students are struggling in class and giving them extra help but as an introduction of this ability to the online learning world.

Social network analysis (SNA) is a set of methods for analyzing the connections between people in a social context, using techniques from the computer science field of network analysis. Social Networks Adapting Pedagogical Practice (SNAPP, http://www.snappvis.org/; Bakharia \& Dawson 2011) is a social network analysis tool specifically developed for online learning contexts (Dawson 2010). SNAPP allows teachers to track learner activity in the forums of a LMS/VLE over time, displaying a social network diagram with the individual learners indicated by a red circle, and the links between them as lines. SNAPP makes it easy for teachers to identify, for instance, learners who are entirely disconnected from the 
network (and hence are not fully participating), or learners who are central to the network (and hence are key enablers of the conversation). It also helps teachers to identify the pattern of interaction in the forum - whether, for example, it is largely teacher-centric, or is more diffuse with stronger peer interaction. Another use is to identify self-contained groups, or cliques, who interact with each other but not with those beyond the group.

The examples discussed so far have concerned essentially quantitative data generated by students. However, advances in computation, in fields such as natural language processing and latent semantic analysis, make it possible to analyze qualitative, textual data - not just in terms of simple frequency counts (how many times particular words are used), but in richer, more meaningful ways. Content and semantic analysis can be used to analyze students' contributions to an online forum, giving them feedback about the degree to which their online talk is exploratory (or matches other criteria for constructive educational dialogue), and offering suggestions for ways in which they might contribute more effectively. Recommendation engines (or recommenders) are computational tools that provide suggestions to individuals for items they may be interested in, based on analysis of the behavior of many users. The most famous example is Amazon's 'Customers Who Bought This Item Also Bought' feature; Amazon also uses a recommendation engine to suggest purchases based on a customer's purchase history and the ratings they have given to other products. The same techniques can be applied in an educational context. So, for example, a system could suggest learning resources to a student based on what resources they have previously used or found helpful, and on other students' behavior and ratings. However, it may be problematic to apply this approach in the context of a conventional university with a set curriculum: students typically are offered relatively little choice about the direction of their study, and so have less need for an automated system to suggest learning resources that might be helpful. It may have more application at higher levels of study, and perhaps the greatest potential benefit lies in more open-ended and less formal learning contexts.

One of the largest expectations of LA research and practice relates to the proposition that it will improve students' learning outcomes. However, according to comprehensive research conducted by (Viberg et al., 2018) this proposition has been confirmed by only few studies (9\%) (Pic. 3).

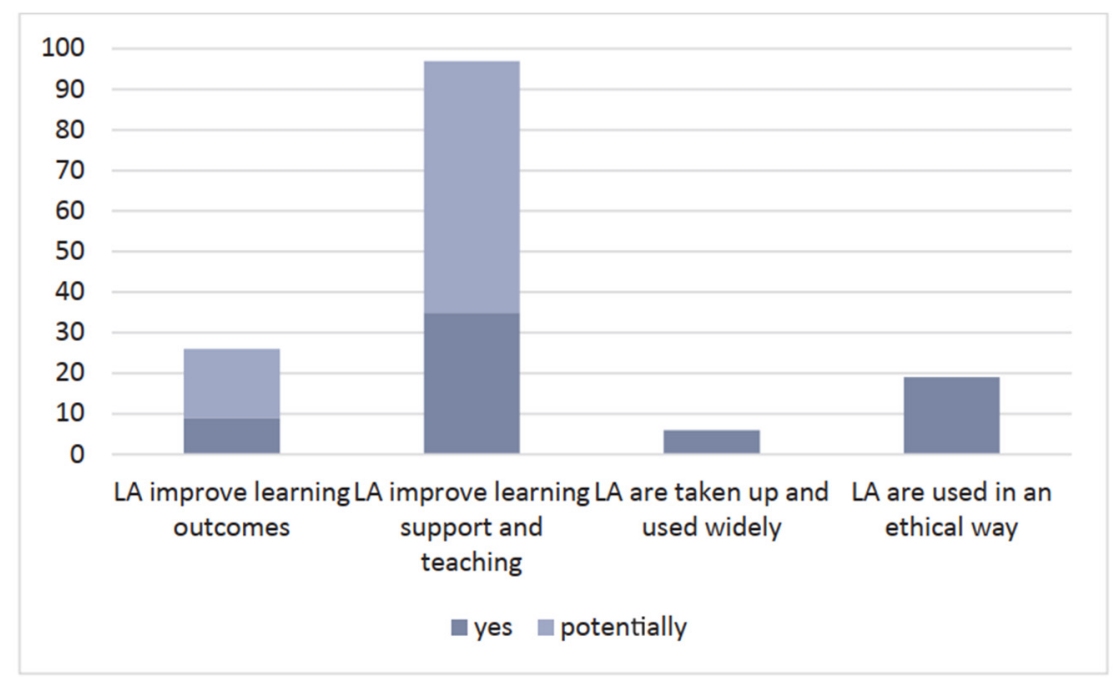

Picture 3: Evidence for learning analytics in higher education (\%) Source: Viberg et al., 2018

Even though the identified potential for improving learning support and teaching, as well as improvements in learning outcomes is high (Pic. 3), we cannot currently see as much transfer of the suggested potential into higher educational practice as it was expected. This raises many questions and the need for rethinking how LA's potential can be more beneficial for HE. Below we will try to highlight some of the barriers and possible causes of this situation:

- As a field, learning analytics is data-driven, and often not explicit about its theoretical basis. Several authors have sought to ground learning analytics in theory (e.g. Clow 2012; Dawson 2008; Atkisson \& Wiley 2011), but this is not universal, running the risk of treating the data that has been gathered as the data that matters. The choice of what is measured - in learning analytics terms, the selection of metrics - is critical. If an educational system is designed to optimize metrics that do not encompass learning, it is likely that learning will be optimized away;

- The application of LA in practice is associated with the use of purpose-developed tools and solutions but, being new and hot, also means that the industry uses the term "learning analytics" in a variety of ways. Some reflect neither the spirit nor the current state of this technology. 


\section{LEARNING ANALYTICS: HOW TO BE MORE SUCCESSFUL}

Despite many promising descriptions of LA, its consideration should always start from the following facts:

- the world is more and more data-driven - education is no exception,

- learning analytics is an important tool to improve education and to make educational institutions more competitive,

- learning analytics is useful only if there is "action" as a result of its implementation, and

- institutions must implement predictive analytics to really benefit from a new way of driving student success.

Implementing learning analytics projects in HE may be challenging. This is especially true for the first LA project, the success of which may be crucial to the attitude of the HE institution regarding further LA efforts. To be successful in implementing LA projects (specially the first one), there are several key elements that need to be considered:

- Start small: The initial LA project should have a limited scope and duration. It is not a good practice to start with an institution-wide project;

- Do not focus on technology: HEIs should focus on specific problems they want to address with their learning analytics project/solution;

- Go after quick wins: Showing by example that learning analytics may improve current learning processes is an effective approach;

- From day one, involve all the critical stakeholders: This will help to get their support in the long run.

Success could also be increased by following a more formal approach towards analytics implementation. There are several learning analytics readiness assessment tools available to HEIs to perform a self-assessment on how equipped they are for their first learning analytics journey. If a HEI has identified an actual problem or a goal that LA can contribute to and a satisfactory level of LA readiness is established, it should initiate a seed project. This seed project should provide the HEI with initial experience it will need in the future, once it starts implementing analytics on a larger scale.

Like any other technology, learning analytics also faces some challenges, which HEIs must be aware of:

- Data capture: Not all student interactions happen in a digital environment. Analytics can only take into account events that provide a digital trace. In other words, learning analytics has a partial view of the educational environment;

- Data variety: As we already described, learning analytics goes beyond the LMS. Combining data coming from multiple sources and systems may be difficult;

- Comparable analytics: How do we compare learning analytics metrics? At the moment, no open standards are defining relevant metrics and, more importantly, metrics significance;

- Predictions accuracy: All conclusions drawn through statistical processes are subject to error. Whether this error is acceptable or not depends on its estimated magnitude and its practical relevance. Learning analytics will never be perfect;

- Partial view: Learning processes go beyond what data tells us. Do not forget we are dealing with humans. There is no equation capable of defining us in full...yet;

- Data literacy: Analytics consumers need the skills to interpret analytics and apply the correct follow-up actions.

In addition to challenges mentioned above, ethics should be emphasized as probably the most relevant aspect to be considered along all stages of the learning analytics process: data collection, analysis, and action. Data, as the primary raw material for learning analytics, is a very sensitive asset. There is a statement that summarizes what should be the correct approach towards data collection: collect as much useful data as possible and as less sensitive data as required. In addition to privacy considerations, we should never forget that we are predicting human failure or success. Therefore, how we come up with those predictions and how we act on them is critical. Being highly sensitive to ethics is definitely a must.

\section{CONCLUSION}

Learning Management Systems have provided statistics showing student progress, average grades, time spent on the platform, etc. But learning analytics goes far beyond the LMS: it is not restricted to data provided by the LMS. Quite the opposite, in LA we are trying to mix LMS data with data coming from other systems in order to enrich data to obtain relevant insights. The game is no longer about average time, average progress, etc.: it is about using machine learning algorithms to predict and proactively act. In other words, as opposed to the descriptive analytic capabilities of LMSs, learning analytics should be predictive.

However, despite LA's suggested potential for improving learning support and teaching, as well as learning outcomes, we have not witnessed much transfer of this potential into the higher education practice over the years. This raises a question of how we can facilitate this transfer for the benefit of learners. The promise of learning analytics is the empowerment of teachers and students to understand the wealth of data that relates to their learning. Engaging in this process is a way of taking control of the agenda, so that the economic framing can be at least supplemented with a concern for learning. It is not a simple or straightforward process, and a focus on the data alone is not sufficient: to achieve 
institutional change, learning analytics data need to be presented and contextualized in ways that can drive organizational development (Macfadyen \& Dawson 2012).

The LA process in higher education is often driven by the demands and worldview of managers and the economic framing of education. There is value — and not just in the economic sense — for teachers having more information about their students. The opportunity afforded by learning analytics is for educators to refuse to be overawed by the process, to understand the tools and techniques, their strengths and limitations, and to use that understanding to improve teaching and learning.

In this paper, focused on the current state of art in the area of LA application, which is burdened by many problems and disappointments regarding the effects achieved, we outlined the most significant issues in the theory and practice of LA, and proposed several practical guidelines and recommendations that could benefit HEIs considering embarking on their first LA adventure. However, additional research is necessary to better understand the potential benefits of LA's for HEIs, with particular focus on opportunities, barriers and challenges.

\section{REFERENCES}

Atkisson, M., \&Wiley, D. (2011). Learning analytics as interpretive practice: applying Westerman to educational intervention. Proceedings of the 1st International Conference on Learning Analytics and Knowledge (LAK11), Banff, AB, Canada, Feb 27 - Mar 01, 2011. New York: ACM, 117-121.

Bakharia, A., \& Dawson, S. (2011). SNAPP: a bird's-eye view of temporal participant interaction. Proceedings of the 1st International Conference on Learning Analytics and Knowledge (LAK11), Banff, AB, Canada, Feb 27 - Mar 01, 2011. New York: ACM, 168-173.

Broadbent, J., \&Poon, W. (2015). Self-regulated learning strategies and academic achievement in online higher education learning environments: A systematic review. The Internet and Higher Education, 27, 1-15.

Campbell, J., \&Oblinger, D. (2007). Academic Analytics. Educause Quarterly, October 2007.

Campbell, J., De Blois, P., \& Oblinger, D. (2007). Academic Analytics: A New Tool for a New Era. Educause Review, 42 (4): 40-57.

Clow, D. (2012). The Learning Analytics Cycle: Closing the Loop Effectively. Proceedings of the 2nd International Conference on Learning Analytics and Knowledge (LAK12), Vancouver, BC, Canada, April 29 - May 02, 2012. New York: ACM, 134-138.

Dawson, S. (2010). 'Seeing' the learning community: An exploration of the development of a resource for monitoring online student networking. British Journal of Educational Technology, 41 (5): 736-752.

Ferguson, R. (2012). The State of Learning Analytics in 2012: A Review and Future Challenges. Technical Report KMI12-01. Milton Keynes: Knowledge Media Institute, The Open University, Retrieved March 15, 2020 from http://kmi.open.ac.uk/publications/techreport/kmi-12-01

Lee, K. (2017). Rethinking the accessibility of online higher education: A historical overview. The Internet and Higher Education, 33, 15-23.

Long, P., \& Siemens, G. (2011). Penetrating the Fog: Analytics in Learning and Education. Educause Review, 46 (5): $31-$ 40.

Macfadyen, L., \& Dawson. S. (2012). Numbers Are Not Enough. Why eLearning Analytics Failed to Inform an Institutional Strategic Plan. Educational Technology and Society, 15 (3), 149-163.

Mah, D.-K. (2016). Learning analytics and digital badges: Potential impact on student retention in higher education. Technology, Knowledge and Learning, 21(3), 285-305.

Schumacher, C., \& Ifenthaler, D. (2018). Features students really expect from learning analytics. Computers in Human Behavior, 7, 397-407.

Strang, K. (2016). Beyond engagement analytics: Which online mixed-data factors predict student learning outcomes? Education and Information Technologies, 20(4), 1-21.

Viberg, O., Hatakka, M., Bälter, O., \&Mavroudi, A. (2018). The current landscape of learning analytics in higher education. Computers in Human Behavior 89 (2018) 98-110. 